\title{
PERFIL DOS DOADORES EFETIVOS DE MÚLTIPLOS ÓRGÃOS E TECIDOS VIABILIZADOS PELA ORGANIZAÇÃO DE PROCURA DE ÓRGÃOS DE UMA INSTITUIÇÃO PÚBLICA DE CARDIOLOGIA
}

\author{
Profile of effective donors of multiple organs and tissues by the Organ Procurement Organization \\ in a public institution of cardiology
}

Carine Cristiane Fusco, César Augusto Guimarães Marcelino, Mara Nogueira Araújo, Andréa Cotait Ayoub, Christiane Pereira Martins

\begin{abstract}
RESUMO
Introdução: Estudo realizado na Organização de Procura de Órgãos (OPO) do Instituto Dante Pazzanese de Cardiologia, com objetivo de descrever o perfil dos doadores de órgãos/tecidos viabilizados. Objetivo: Caracterizar os doadores entre 1998 e 2005 quanto ao sexo, idade, estado civil, cor, escolaridade, causa da morte encefálica (ME), tipo de notificação, setor notificante, responsável legal pela doação, órgãos/ tecidos disponibilizados e, posteriormente, relacionar as causas da ME com sexo e idade. Método: Exploratório, descritivo, documental. Resultado: A amostra totalizou 241 doadores, prevalecendo o sexo masculino em 151 (62,7\%) casos, com faixa etária entre 7 a 74 anos, $116(48,1 \%)$ solteiros, 174 (72,2\%) de raça branca e 103 (42,7\%) com ensino fundamental incompleto. Do total das notificações, $205(85,1 \%)$ foram notificadas pelo hospital de origem do potencial doador, prevalecendo a Unidade de Terapia Intensiva com 123 (51\%) casos. Como causas da ME, destacam-se Traumatismo Crânio-Encefálico (TCE) com 94 (39\%) casos e Acidente Vascular Encefálico Hemorrágico (AVEH) com $63(26,1 \%)$ casos. Em relação aos responsáveis pela doação, $118(49 \%)$ casos possuíam parentesco de $1^{\circ}$ grau. Os órgãos/ tecidos mais captados foram: coração 132 (54,8\%), fígado 210 (87,1\%), rim $428(88,8 \%)$ e córneas 191 (79,3\%). Comparando as causas de ME com sexo e idade, observou-se maior incidência de AVEH em mulheres, com $38(42,2 \%)$ casos e idade média de 43.6 anos; nos homens houve predomínio de TCE, 76 (50,7\%) casos, e ferimento por arma de fogo com 24 (16\%) casos. Conclusão: Houve predomínio de doadores do sexo masculino, solteiros, tendo como causa de morte encefálica traumas e doenças vasculares, além de menor número de captação de pulmões, intestino e pâncreas, bem como valvas, ossos, vasos, pele, músculos e tendões.
\end{abstract}

Descritores: Doadores de Órgãos, Doadores de Tecidos, Morte Encefálica, transplante de órgãos e transplante de tecidos.

Instituição:

Organização de Procura de Órgãos, Instituição Dante Pazzanese de Cardiologia - São Paulo / SP

\section{Correspondência:}

Carine Cristiane Fusco

Rua Araçatuba, 109 - São Caetano do Sul - São Paulo / SP - CEP: 09570-130 - Brasil

Tel.: (11) 93793503 / (11) 55718601

E-mail: carine_fusco@hotmail.com

Recebido em: 22.06.2009

Aceito em: 10.07.2009

\section{INTRODUÇÃO}

O Instituto Dante Pazzanese de Cardiologia (IDPC) é uma instituição pública, que tem como filosofia o ensino, pesquisa e assistência. É um hospital de grande porte, de referência cardiovascular e que se encontra em processo de expansão. É composto por diversos setores, sendo um deles a Organização de Procura de Órgãos (OPO).

A OPO do IDPC surgiu em 1998, baseada no Decreto $\mathrm{n}^{\circ} 2268,{ }^{1}$ sendo definida como entidade sem fins lucrativos com atuação regionalizada para detecção de doador potencial, constituída por um ou mais hospitais de sua área territorial de atuação. (Resolução $\left.\mathrm{n}^{\mathrm{o}} 103,1997\right){ }^{2}$

A doação de órgãos é assunto de grande atualidade e imensa dimensão.

Os transplantes de órgãos representaram de forma progressiva, a partir da década de 60, um dos mais importantes avanços da Medicina. Superando dificuldades e gerando conhecimentos que impulsionaram a ciência médica como um todo, os transplantes popularizaram-se a ponto de que a maioria dos órgãos e tecidos podem ser atualmente transplantados.,3,4 
Obedecendo determinação do Decreto Federal 2.268/97 que regulamenta a Lei Federal 9.434/97, o Secretário de Estado da Saúde de São Paulo criou e regulamentou o Sistema Estadual de Transplantes (SET) integrante do Sistema Nacional de Transplantes (SNT), que, em última análise, estabelece a maneira como os órgãos e tecidos de doadores falecidos são captados e distribuídos no Estado de São Paulo, conforme legislação em vigor. ${ }^{4}$

O SET compreende seis módulos, sendo eles: Transplante de Coração, Fígado, Rim, Pulmão, Pâncreas Isolado e Rim/Pâncreas, e de Córneas. ${ }^{4}$

O Módulo de Transplante define a estrutura das entidades integrantes, as atribuições e a operacionalização das atividades para notificação, captação e distribuição de órgãos e tecidos de falecidos. As Entidades são as Instituições, Unidades e/ou Equipes que integram o SET. ${ }^{4}$

Todo processo de doação/transplante está regulamentado pela Lei $n^{\circ} 9434 / 97$, que dispõe sobre a remoção de órgãos, tecidos e partes do corpo humano para fins de transplante e tratamento.

Tendo os enfermeiros da OPO a função de identificar e efetivar potenciais doadores provenientes de sua área de atuação, surgiu a necessidade de caracterizar os doadores efetivos desde o início das atividades da OPO-Dante até o final de 2005, para formar um perfil desses doadores tanto quanto aos dados pessoais como dados relevantes ao processo doação-transplante, para que tivesse início atividades educativas dentro dos hospitais.

\section{OBJETIVOS}

- Caracterizar os doadores efetivos de órgãos e tecidos de uma OPO, entre 1998 a 2005;

- Levantar as causas de morte encefálica, tipos de notificações, setor notificante, responsável legal pela doação, órgãos e tecidos mais e menos captados pelas equipes transplantadoras;

- Relacionar a causa da morte encefálica com sexo e idade.

\section{MÉTODO}

O estudo foi do tipo retrospectivo descritivo, realizado na OPO de uma instituição pública da cidade de São Paulo referência em doenças cardiovasculares, considerada também uma instituição captadora e transplantadora cardíaca, renal e hepática.

A pesquisa bibliográfica foi realizada nas bases de dados MEDLINE, LILACS e SECRETARIA DA SAÚDE, utilizando como palavra chave doação de órgãos. Foram analisados todos os prontuários e fichas de notificações dos doadores de múltiplos órgãos e tecidos, além do livro de registro interno da OPO no período de 1998 a 2005, totalizando uma amostra de 241 doadores. A área de abrangência da OPO é de aproximadamente cinco milhões de habitantes, tendo uma média em sete anos de 35 (trinta e cinco) doadores/ano, totalizando sete doadores por milhão de população.

Foi elaborado um instrumento em duas planilhas com 23 variáveis, sendo que destas, cinco eram para caracterização pessoal dos doadores: sexo, idade, estado civil, cor e escolaridade. As demais dezoito variáveis eram referentes ao processo de captação e doação de órgãos/tecidos: causa da morte encefálica, tipo de notificação (espontânea, busca ativa por telefone e visita aos hospitais), setor notificante, responsável legal pela doação (parentes de $1^{\circ}$ ou $2^{\circ}$ grau, cônjuge ou amasiado) e órgãos e tecidos captados ou não pelas equipes transplantadoras (coração, pulmão, fígado, rim, pâncreas, intestino, córneas, osso, pele, vasos, músculo, tendão e valvas).
Os dados coletados foram colocados em duas planilhas e foi elaborada uma listagem dos códigos utilizados (“code book”), cada uma das variáveis contendo seus respectivos códigos.

Realizou-se análise descritiva dos dados com o objetivo de caracterizar a amostra quanto ao sexo, idade, estado civil, cor, escolaridade, causa da morte encefálica, tipo de notificação (espontânea, busca ativa por telefone ou visita aos hospitais), setor notificante, responsável legal pela doação, órgãos e tecidos captados ou não pelas equipes transplantadoras. Para comparação múltipla entre causa da morte encefálica com idade e sexo, foi utilizado o teste do qui-quadrado, para avaliar a associação ou não dos dados obtidos.

\section{Aspecto Ético}

O projeto foi aprovado pelo Comitê de Ética em Pesquisa do Instituto Dante Pazzanese de Cardiologia com número de protocolo 3444 do ano de 2007.

\section{RESULTADOS}

Quanto à caracterização da amostra, dos 241 doadores do estudo, 151 (62.7\%) eram homens e 90 (37.3\%) mulheres, com faixa etária variando de sete a 74 anos de idade. Quanto ao estado civil, 116 (48.1\%) eram solteiros e 92 (38.2\%) casados. Em relação à cor, 174 (72.2\%) eram brancos e 32 (13.3\%) pardos. Referente à escolaridade, 103 (42.7\%) possuíam ensino fundamental incompleto, 50 (20.7\%) ensino fundamental completo e 39 (16.2\%) ensino médio completo. (Tabela 1)

Quanto ao tipo de notificação, 205 (85.1\%) foram espontâneas, ou seja, identificadas pelo próprio hospital onde se encontrava o doador. Com referência ao setor de origem do doador, 123 (51\%) foram encontrados nas unidades de Terapia Intensiva - Adulta e 61 (25.3\%) em unidades de Emergência. Das variáveis referentes às causas da morte encefálica, as que mais se sobressaíram foram: 94

Tabela 1. Caracterização da amostra. São Paulo, 2006

\begin{tabular}{|c|c|c|c|}
\hline & & $\mathrm{N}(241)$ & $\%$ \\
\hline \multirow[t]{2}{*}{ Sexo } & Masculino & 151 & 62.7 \\
\hline & Feminino & 90 & 37.3 \\
\hline \multirow[t]{5}{*}{ Estado Civil } & Solteiro & 116 & 48.1 \\
\hline & Casado & 92 & 38.2 \\
\hline & Amasiados & 13 & 5.4 \\
\hline & Separados & 10 & 4.1 \\
\hline & Viúvos & 5 & 2.1 \\
\hline \multirow[t]{4}{*}{ Cor } & Branco & 174 & 72.2 \\
\hline & Pardo & 32 & 13.3 \\
\hline & Negros & 22 & 9.1 \\
\hline & Amarelo & 1 & 0.4 \\
\hline \multirow[t]{6}{*}{ Escolaridade } & Fund. Incompleto & 103 & 42.7 \\
\hline & Fund. Completo & 50 & 20.7 \\
\hline & Médio Completo & 39 & 16.2 \\
\hline & Médio Incompleto & 20 & 8.3 \\
\hline & Superior Completo & 10 & 4.1 \\
\hline & Superior Incompleto & 8 & 3.3 \\
\hline
\end{tabular}


(39\%) casos de Traumatismo Crânio Encefálico (TCE), 63 (26.1\%) de Acidente Vascular Encefálico Hemorrágico (AVEH) e 28 (11.6\%) de Ferimento por arma de fogo (FAF).

Ao analisar o grau de parentesco do responsável pela doação de órgãos/tecidos, observou-se que 118 (49\%) eram parentes de $1^{\circ}$ grau e 83 (34.4\%), cônjuges. (Tabela 2)

Os órgãos e tecidos mais captados pelas equipes transplantadoras foram: rim 428 (88.8\%), fígado 210 (87.1\%), coração 132 (54.8\%), córnea 191 (79.3\%); já os menos captados foram: intestino 241 (100\%), pulmão 229 (95\%), pâncreas 164 (68\%), músculo/tendão 241 (100\%), valvas cardíacas 227 (94.2\%), ossos 219 (90.9\%), vasos 203 (84.2\%) e pele 200 (83\%). (Tabela 3).

Ao realizar uma comparação entre causas da morte encefálica com o sexo dos doadores, o que se observou foi que Acidente Vascular Encefálico Hemorrágico (AVEH) atinge em sua maioria mulheres (42.2\%). Ao contrário de Traumatismo Crânio Encefálico (TCE) e

Tabela 2. Variáveis sobre processo de captação de órgãos e tecidos. São Paulo, 2006

\begin{tabular}{|c|c|c|c|}
\hline & & $N(241)$ & $(\%)$ \\
\hline \multirow[t]{3}{*}{ Tipo Notificação } & Espontânea & 205 & 85,1 \\
\hline & Busca Hospitais & 1 & 0.4 \\
\hline & Sem informação & 35 & 14,5 \\
\hline \multirow[t]{5}{*}{ Setor Notificante } & UTI Adulto & 123 & 51,0 \\
\hline & Emergência & 61 & 25,3 \\
\hline & UTI Infantil & 4 & 1.7 \\
\hline & Outros & 3 & 1.2 \\
\hline & Sem informação & 50 & 20.7 \\
\hline \multirow[t]{5}{*}{ Causas ME } & TCE & 94 & 39,0 \\
\hline & $\mathrm{AVCH}$ & 63 & 26,1 \\
\hline & FAF & 28 & 11,6 \\
\hline & Outros & 55 & 22.8 \\
\hline & Sem informação & 1 & 0.4 \\
\hline \multirow[t]{5}{*}{ Responsável Legal } & $1^{\circ} \mathrm{Grau}$ & 118 & 49,0 \\
\hline & Cônjuge & 83 & 34,4 \\
\hline & $2^{\circ} \mathrm{Grau}$ & 33 & 13.7 \\
\hline & Amasiado & 3 & 1.2 \\
\hline & Sem informação & 4 & 1,7 \\
\hline
\end{tabular}

Tabela 3. Órgãos e Tecidos mais e menos captados. São Paulo, 2006

\begin{tabular}{|c|c|c|}
\hline & ÓRGÃOS & TECIDOS \\
\hline \multirow[t]{3}{*}{ CAPTADOS } & $\operatorname{Rim}-428(88,8 \%)$ & Córneas - 191 (79,3\%) \\
\hline & Fígado - $210(87,1 \%)$ & \\
\hline & Coração -132 (54,8\%) & \\
\hline \multirow[t]{5}{*}{ NÃO CAPTADOS } & Intestino - $241(100 \%)$ & Músculo/Tendão - 241 (100\%) \\
\hline & Pulmão - 229 (95\%) & Valvas - $227(94,2 \%)$ \\
\hline & Pâncreas - 164 (68\%) & Osso - $219(90,9 \%)$ \\
\hline & & Vasos - $203(84,2 \%)$ \\
\hline & & Pele - 200 ( 83\%) \\
\hline
\end{tabular}

Tabela 4. Causas da morte encefálica, sexo e idade média. São Paulo, 2006

\begin{tabular}{llll}
\hline & N (\%) & SEXO & $\begin{array}{l}\text { IDADE MÉDIA } \\
\text { (anos) }\end{array}$ \\
\hline TCE (94) & $76(50,7 \%)$ & Masculino & 26,6 \\
AVCH (63) & $38(42,2 \%)$ & Feminino & 43,6 \\
FAF (28) & $24(16,0 \%)$ & Masculino & 25,0 \\
Outros (55) & $55(23 \%)$ & Masc./Fem. & 36,0 à 46,0 \\
\hline
\end{tabular}

Teste do Qui-Quadrado

de Ferimento por Arma de Fogo (FAF), que atingem mais homens: $50.7 \%$ e $16 \%$, respectivamente. Comparando as causas de morte encefálica com idade, observou-se que os doadores que faleceram de AVCH tinham média de idade de 43,62 anos; TCE de 26,57 anos e FAF 24,14 anos. (Tabela 4)

\section{DISCUSSÃO}

O Processo de doação de órgãos e tecidos para transplante é considerado complexo e tem início com a detecção de um potencial doador dentro de um hospital notificante e finaliza com o transplante, caso a família tenha concordado com a doação dos órgãos.

Existem três diferentes meios de identificação de um potencial doador: busca ativa por telefone, visita aos hospitais notificadores e notificação espontânea. A busca ativa por telefone ou por visita hospitalar é feita por membros da OPO que entram em contato com os hospitais ou se dirigirem até os mesmos, verificando com os profissionais de saúde se há ou não algum potencial doador dentro de seu setor. A notificação espontânea consiste de o próprio hospital identificar e notificar a Central de Transplantes ou sua OPO correspondente sobre a existência desse potencial doador.

A notificação de paciente que esteja em morte encefálica é compulsória desde novembro de 1992, através da Lei 8.489, porém, sabemos que ainda existem muitas subnotificações por parte dos hospitais. Neste trabalho, verificamos que dos 241 doadores efetivos, a maioria das notificações foi espontânea, totalizando 205 (85.1\%) casos, mostrando assim melhora gradual de conscientização dos profissionais frente à possibilidade de doação de órgãos quando se deparam com pacientes que preenchem os critérios de morte encefálica.

Essas buscas são realizadas geralmente em unidades de terapia intensiva e emergência, já que é nesses setores que se encontram pacientes com quadro geral grave. Esses dados vão ao encontro com o que observamos nesta pesquisa, onde 123 (51\%) dos casos estavam locados em unidades de terapia intensiva e 61 (25.3\%) em emergência. Torna-se importante essa informação, pois dessa forma, podemos desenvolver atividades educativas em especial nesses setores, além de estreitar os vínculos com esses profissionais.

Frente às causas da morte encefálica, as que mais se sobressaíram foram: Traumatismo Crânio Encefálico (TCE) com 94 (39\%) casos e Acidente Vascular Encefálico Hemorrágico (AVEH) com 63 (26.1\%) casos. Esses dados defrontam os dados obtidos no Registro Brasileiro de Transplante, ${ }^{5}$ onde no primeiro semestre de 2009, houve no Estado de São Paulo 119 casos de morte por TCE e 190 por AVE, mostrando a mudança de perfil dos potenciais doadores nestes últimos quatro anos. Tal mudança pode estar relacionada com a diminuição de acidentes automobilísticos, associado à Lei 11.705 de 19 de Junho de 
2008 (“Lei Seca”), apesar do Brasil ainda ser o quinto país com maior número de mortes por acidente de trânsito. Segundo a Organização Mundial de Saúde, no ano de 2007 o Brasil teve um total de 35 mil mortes causadas por desastres automobilísticos, taxa superior à dos EUA (13) e inferior à da Rússia (25). ${ }^{6}$

Ao levantarmos dados sobre órgãos e tecidos menos captados, podemos observar que quanto aos órgãos, sobressaíram-se intestino, pulmão e pâncreas. Com referência aos tecidos, foram músculo/tendão, valvas cardíacas, ossos, vasos e pele. Quanto a não extração desses tecidos, acreditamos que isso pode ser atribuído ao conhecimento restrito da população sobre a possibilidade de doação, sem que haja prejuízo para a reconstituição do corpo do doador. Com referência ao não aproveitamento desses órgãos pelas equipes transplantadoras, pode ser devido à idade ou a antecedentes pessoais, entre outros fatores.

Ao se realizar uma comparação entre causas da morte encefálica com o sexo e idade dos doadores, o que se observou é que Acidente Vascular Encefálico Hemorrágico (AVEH) atinge em sua maioria mulheres (42.2\%), com uma média de idade de 43,62 anos, ao contrário de Traumatismo Crânio Encefálico (TCE) que atinge mais homens (50.7\%), com média de idade de 26,57 anos. Tais dados vão ao encontro do trabalho realizado por Pestana ${ }^{7}$ em 1992, onde ele avalia o número de potenciais doadores na cidade de São Paulo através das necropsias realizadas por morte violenta nos anos de 1990 e 1991 . Aquele trabalho demonstrou que a maioria de mortes violentas foi caracterizada pelo sexo masculino (86\% e $85 \%$, respectivamente aos anos de 90 e 91), na faixa etária entre
15 a 45 anos (78\% e 72\%, também respectivamente). Porém, tais dados, ao serem comparados atualmente com o Registro Brasileiro de Transplante, 5 mostram uma realidade inversa já discutida acima, onde a maior causa de morte encefálica seria de causa vascular, que, segundo o Ministério da Saúde, tende a aumentar devido à maior sobrevida da população. ${ }^{8,9}$

\section{CONCLUSÃO}

Com este estudo, foi possível conhecer o perfil dos doadores efetivos de órgãos e tecidos da OPO desde o início de sua implantação em 1998 até o final de 2005, onde, dos 241 doadores desta pesquisa, $62.7 \%$ eram do sexo masculino, prevalecendo solteiros (48.1\%), de raça branca (72.2\%) e com ensino fundamental incompleto (42.7\%). Do total de notificações, $85.1 \%$ foram feitas pelo próprio hospital onde se encontrava o doador, tendo como setor prevalente a Unidade de Terapia Intensiva - Adulta (51\%), e se destacando como causa de morte encefálica Traumatismo Crânio-Encefálico (TCE) (39\%) e Acidente Vascular Encefálico Hemorrágico (AVEH) (26.1\%). Como responsável legal pelas doações, $49 \%$ era parente de $1^{\circ}$ grau. Os órgãos e tecidos mais captados pelas equipes transplantadoras foram o rim (88.8\%), fígado (87.1\%), coração (54.8\%) e córnea $(79.9 \%)$.

Ao comparar as causas de ME com sexo e idade, verificou-se que as mulheres (42.2\%) morrem mais de AVCH, com idade média (43.6 anos) mais avançada que os homens, que morrem mais de TCE (50.7\%) e FAF (16\%).

\section{ABSTRACT}

Introduction: A study carried out in the Organ Procurement Organization (OPO) of the Institute Dante Pazzanese of Cardiology, aiming to describe the profile of effective donors of organs and tissues. Purpose: To characterize donors between 1998 and 2005 , by sex, age, marital status, race, education, cause of brain death (BD), type of notification, notifying sector, legal responsible for the donation, available organ/tissue and later correlating causes of BD to sex and age. Method: Exploratory, descriptive, documentary. Results: Sample included 241 donors, prevailing male in 151 (62.7\%) cases, with ages between 7 and 74, 116 (48.1\%) single, 174 (72.2\%), Caucasian, and 103 (42.7\%) with non complete elementary education. Based on total notifications, $205(85.1 \%)$ were notified by the hospital of origin of the potential donor, prevailing the Intensive Care Unit with 123 (51\%) cases. Causes of BD were mainly Traumatic Brain Injury (TBI) with 94 (39\%) cases, and hemorrhagic stroke (HS) with 63 (26.1\%) cases. For those responsible for the donation, 118 (49\%) cases had a close relative. Most of the harvested organs/tissues were: heart 132 (54.8\%), liver 210 (87.1\%), kidney 428 (88.8\%) and corneas 191 (79.3\%). Comparing the causes of BD to sex and age, a higher incidence of stroke in women with $38(42.2 \%)$ cases and mean age of 46.6 years was observed. As to men, there was a prevalence of TBI, 76 (50.7\%) cases and injury by fire gun with 24 (16\%) cases. Conclusion: Based on the results, the majority were male, single donors, with causes of brain death of trauma and vascular disease. Plus, the low amount of harvested lungs, intestine and pancreas, as well as valves, bones, vessels, skin, muscles and tendons.

Keywords: Organ Donors, Tissue Donors, Brain Death, Organ transplantation, Tissue Transplantation.

\section{REFERÊNCIAS}

1. Decreto $n^{\circ} 2268$ de 30 de Junho de 1997. Regulamenta a Lei n ${ }^{\circ} 9434$ de 4 de fevereiro de 1997, que dispõe sobre a remoção de órgãos, tecidos e partes do corpo humano para fins de transplante e tratamento, e dá outras providências. DOU de 01 de Julho de 1997 - seção 1 - p. 13.739, Brasília - DF

2. Resolução SS-103 de 01 de agosto de 1997. Dispõe sobre a estrutura organizacional e operacional do Sistema Estadual de Transplante de São Paulo. Diário Oficial do Estado de São Paulo de 1997 - seção 1 - p. 15 a 20.

3. Camargo J, Garcia V, Hoefelmann N, Neumann J e Comissão de Transplantes de Órgãos da Santa Casa de Porto Alegre. Doação de Órgãos - Uma Responsabilidade de Todos. Revista Médica Santa Casa. Porto Alegre (RGS), 1994;5(10):1095-9.
4. Brasil. Resolução SS - 128 de 31 de Dezembro de 2003.

5. Registro Brasileiro de Transplantes. Órgão Oficial da Associação Brasileira de Transplantes de Órgãos - ABTO. Ano XV - nº 2 - Janeiro/Junho 2009.

6. http://www.portaldotransito.com.br/noticias/brasil-e-quinto-pais-do-mundo-emmortes-por-acidentes-de-transito.html em 17 de junho de 2009.

7. Pestana JOM, Vaz MLS, Delmonte CA, Cavecchia SR, Pacheco M, Piveta VM, Batista JC, Ramos OL, Ajzen H. Estimativa do número de potenciais doadores de órgãos na cidade de São Paulo. Rev Ass Méd Brasil; 1992;38(2):97-100.

8. Brasil. Ministério da Saúde. DATASUS. Website: www.datasus.gov.br

9. Nothen RR. Associação de Medicina Intensiva Brasileira - A doação de Órgãos no cenário da Unidade de Terapia Intensiva, 2006. 